\title{
Differential rabbit eyelid conditioning: Effect of magnesium pemoline ${ }^{1}$
}

PETER W. FREY AND THOMAS J. MISFELDT UNIVERSITY OF WISCONSIN

Magnesium pemoline failed to show reliable effects upon either mixed phase $(10 \mathrm{mg} / \mathrm{kg})$ or separate phase $(15 \mathrm{mg} / \mathrm{kg})$ differential eyelid conditioning in rabbits. Excellent differential responding was observed, indicating that rabbit eyelid conditioning is a suitable technique for studying differential classical conditioning in infra-humans.

The present study was designed to study the effect of magnesium pemoline upon mixed and separate phase differential eyelid conditioning in the rabbit. The dose levels used (10 and $15 \mathrm{mg} / \mathrm{kg}$ ) failed to produce reliable effects in these situations. The rapid development of excellent differential responding, however, indicated that the rabbit eyelid conditioning technique would be useful for studying differential classical conditioning in infrahumans.

For the most part, differential classical conditioning in this country has involved human Ss. Often the interpretation of human conditioning data in terms of basic processes has been complicated by intervention of uniquely human factors, e.g., cognitive sets (Spence, 1966). One way to minimize these factors is to condition laboratory animals rather than humans. In a recent study (Frey \& Ross, 1967), differential eyelid conditioning was demonstrated in the rabbit over a six day training period using dissimilar tones (800 and 2500 $\mathrm{Hz}$ ). In the present study, more rapid differential conditioning was observed with tones of greater similarity. This improved rate of acquisition was correlated with the use of a more intense US, shorter intertrial intervals (ITIs), and shorter interstimulus intervals (ISIs). Method

The Ss were male New Zealand white rabbits weighing 4.5-6.0 lbs. Each $\mathrm{S}$ was caged individually and had free access to food and water. The conditioning procedure and apparatus have been described in detail previously (Frey \& Ross, 1967). Each $S$ is placed in a restraining stock in a sound attenuated chamber. Eyelid movements are graphically recorded using a spring return micropotentiometer which is attached to the S's skull. The shock US is presented to the S's cheek via two implanted wire electrodes. After delivery by a local supplier and preliminary surgery, the rabbits are habituated in a standard procedure prior to the conditioning sessions. For all Ss, the tone CSs were $12 \mathrm{~dB}$ above a constant chamber white noise level of $64 \mathrm{~dB}$ (SPL) and the US was a $100 \mathrm{msec}, 3.6 \mathrm{~mA}$ electric shock delivered to the S's right cheek during the last $100 \mathrm{msec}$ of the tone CS. An electronic pick-off unit recorded CRs which met a criterion of a $2 \mathrm{~mm}$ movement of the recording pen during the ISI.

\section{Experiment 1}

Four days of differential training were given to 24 rabbits with CS tones of 800 and $1200 \mathrm{~Hz}$ and a 700 msec ISI. Each day, 120 trials were given (60/cue) with a 2 min ITI. Half of the Ss were given daily oral administration of magnesium pemoline $(10 \mathrm{mg} / \mathrm{kg})$ 20 min prior to the start of each session. Control Ss received an equal volume of the vehicle alone. No reliable drug effects were observed.

Figure 1 presents the differential conditioning performance of a relatively homogeneous group of Ss, i.e., 12 which started conditioning prior to or during Day 3. The selection of a homogeneous group provides a group learning curve which is more representative of individual performances. Response levels on the first day were close to random blink levels. On Day 2, differential responding was observed, but response rate increased to both cues within the session. On Day 4, a marked within session decrease in response rate to $S-$ occurred (number of responses in first half vs number in second half; sign test-11 plus, 0 minus, 1 tie-p<.001), but a similar tendency was noted for S+ (first half vs second half; sign test-11 plus, 1 minus, 0 ties $-p<.01$ ). Differential responding improved each day over the four sessions (number of responses to St vs number of responses to S-: Day $4>$ Day $3>$ Day 2 $>$ Day 1; sign test-11 plus, 1 minus, 0 ties $-p<.01$ ). Experiment 2

Two days of training were given 16 rabbits in a separate phase differential conditioning procedure. On the first day, 300 single cue trials were given with a $1 \mathrm{~min}$ ITI. On Day 2, an S- was introduced, with 300 trials to each cue and a $30 \mathrm{sec}$ ITI. On both days the ISI was $600 \mathrm{msec}$. Tones of 600 and $800 \mathrm{~Hz}$ were em-

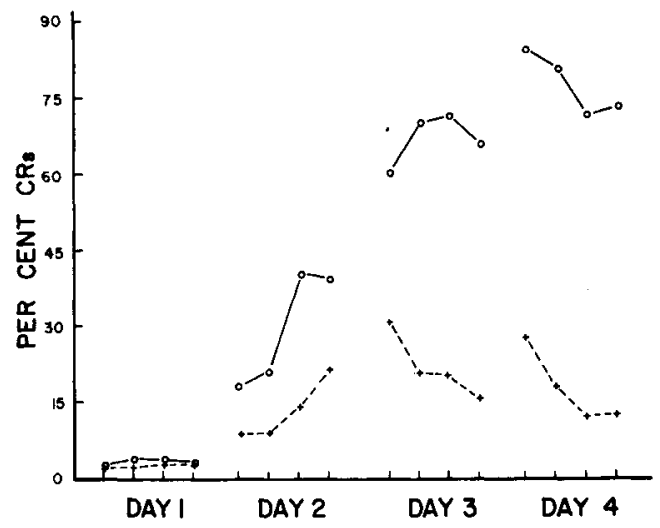

Fig. 1. Mixed phase differential conditioning of the rabbit eyelid response with a $700 \mathrm{msec}$ ISI and tones of 800 and $1200 \mathrm{~Hz}$. Data are plotted in blocks of 15 trials. 


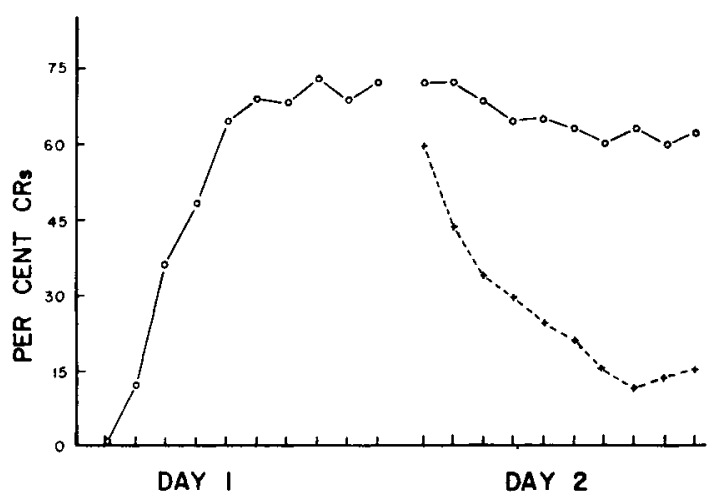

Fig. 2. Separate phase differential conditioning of the rabbit eyelid response with a $600 \mathrm{msec}$ ISI and tones of 600 and $800 \mathrm{~Hz}$. Data are plotted in blocks of 30 trials.

ployed as CSs. Magnesium pemoline $(15 \mathrm{mg} / \mathrm{kg})$ was administered orally (No. 8 French catheter) to each $\mathrm{S}$ on one of the two conditioning days 20 min prior to the start of the session. An equal volume of the vehicle was given on the nondrug day. No reliable drug effects were observed.

Figure 2 presents the response record for $12 \mathrm{Ss}$ which started conditioning during the first session. Rapid acquisition of the CR occurred on Day 1. A high level of generalization to S- was noted on Day 2 when it was first introduced. With continued training, differential responding gradually developed, mostly as a result of decreased responding to S-. A slight decrement in response rate to $S+$ was noted with the session on Day 2 (number of responses in the first half vs that in the second half: sign test-11 plus, 1 minus, 0 ties, $\mathrm{p}<.01$ ).

\section{Discussion}

In instrumental avoidance, magnesium pemoline appears to disrupt the normally observed motor inhibition elicited by fear arousing stimuli, thereby facilitating active avoidance (Beach \& Kimble, 1967; Frey \& Polidora, 1967) and hindering passive avoidance (Gurowitz et al, 1967). This effect may be partially related to the drug's central stimulant action (Lange, Candon, \& Cessin, 1962), but probably not totally so since other potent central stimulants (e.g., methamphetamine, methylphenidate) are not as effective in facilitating active avoidance (Plotnikoff, 1966). Recently, Swadlow \& Schneiderman (1967) have reported that magnesium pemoline enhances differential conditioning of the sympathetically mediated heart rate response but not of a skeletally mediated nictitating membrane response. The present results with the eyelid response are consistent with their data. The information presently available suggests that in addition to general central stimulation, magnesium pemoline has a more selective action upon autonomic-emotional systems.
The present study indicated that excellent differential conditioning occurs in rabbits at ISIs which are shorter than the 800 msec optimum reported for humans by Hartman \& Grant (1962). The rabbits' differential responding ability was equal to or better than that reported for humans responding to similarly spaced tones with an $800 \mathrm{msec}$ ISI (Moore, 1964). The demonstration of excellent differential conditioning in the rabbit under several different procedures indicates the generality of this phenomenon and recommends the rabbit eyelid response for investigating differential classical conditioning in infrahumans.

Both the mixed and separate phase Ss in the present studies demonstrated a within session decrement to St during differential training. In the last day of training for both studies, performance declined to both cues within the session. These within session decrements, which have also been reported in human eyelid conditioning (Runquist \& Muir, 1965; Muir \& Runquist, 1965), may be due to fatigue effects, or to generalized inhibition from S- to S+, or both.

\section{References}

BEACH, G. \& KIMBLE, D. P. Activity and responsitivity in rats after magnesium pemoline injections. Science, 1967, 155, 698-701.

FREY, P. W. \& POLIDORA, V. J. Magnesium pemoline: Effect on avoidance conditioning in rats. Science, 1967, 155, 1281-1282.

FREY, P. W. \& ROSS, L. E. Differential conditioning of the rabbit eyelid response with an examination of Pavlov's induction hypothesis. J. comp. physiol. Psychol., in press. (Oct., 1967).

GUROWITZ, E. M., LUBAR, J. F., AIN, B. R., \& GROSS, D. A. Disruption of passive avoidance learning by magnesium pemoline. Psychon. Sci., 1967, 8, 19-20.

HARTMAN, T. F., \& GRANT, D. A. Differential eyelid conditioning as a function of the CS-UCS interval. J. exp. Psychol., 1962, 64, 131-136.

LANGE, W. E., CANDON, B. H., \& CHESSIN, M. Metal chelates of oxazolidinones as central nervous system stimulants. $J$. Pharm. Sci., 1962, 51, 477-482.

MOORE, J. W. Differential eyelid conditioning as a function of the frequency and intensity of auditory CSs. J. exp. Psychol., 1964, 68, 250-259.

MUIR, W. R., \& RUNQUIST, W. N. Extended differential conditioning of the classically conditioned eyeblink reflex. Psychon. Sci., 1965, 3, $581-582$.

PLOTNIKOFF, N. Magnesium pemoline: enhancement of learning and memory of a conditioned avoidance response. Science, 1966, 151, $703-704$.

RUNQUIST, W. N., \& MUIR, W. R. Intrasession decrements in the performance of the classically conditioned eyelid reflex. $J$. exp. Psychol, 1965, 70, 520-525.

SPENCE, K. W. Cognitive and drive factors in the extinction of the conditioned eyeblink in human subjects. Psychol. Rev., 1966, $73,445-458$.

SWADLOW, H., \& SCHNEIDERMAN, N. Magnesium pemoline: Facilitation and debilitation of heart rate classical discrimination conditioning in rabbits. Psychon. Sci., 1967, 8, 481-482.

Note

1. This research was supported by a Public Health Service Fellowship, No. 24587, from the National Institutes of Health to PWF and by a National Science Foundation Undergraduate Research Participation Program, GY-833. 